\title{
Metabolic Engineering for Unusual Lipid Production in Yarrowia lipolytica
}

\author{
Young-Kyoung Park * (D) and Jean-Marc Nicaud \\ Micalis Institute, AgroParisTech, INRAE, Université Paris-Saclay, 78352 Jouy-en-Josas, France; \\ jean-marc.nicaud@inrae.fr \\ * Correspondence: YoungKyoung.Park@inrae.fr; Tel.: +33-(0)1-74-07-16-92
}

Received: 14 November 2020; Accepted: 2 December 2020; Published: 6 December 2020

check for updates

\begin{abstract}
Using microorganisms as lipid-production factories holds promise as an alternative method for generating petroleum-based chemicals. The non-conventional yeast Yarrowia lipolytica is an excellent microbial chassis; for example, it can accumulate high levels of lipids and use a broad range of substrates. Furthermore, it is a species for which an array of efficient genetic engineering tools is available. To date, extensive work has been done to metabolically engineer Y. lipolytica to produce usual and unusual lipids. Unusual lipids are scarce in nature but have several useful applications. As a result, they are increasingly becoming the targets of metabolic engineering. Unusual lipids have distinct structures; they can be generated by engineering endogenous lipid synthesis or by introducing heterologous enzymes to alter the functional groups of fatty acids. In this review, we describe current metabolic engineering strategies for improving lipid production and highlight recent researches on unusual lipid production in Y. lipolytica.
\end{abstract}

Keywords: Yarrowia lipolytica; oleochemicals; lipids; unusual lipids; metabolic engineering

\section{Introduction}

Microbial lipids are promising alternative fuel sources given growing concerns about climate change and environmental pollution [1-4]. They offer multiple advantages over plant oils and animal fats. For example, the production of microbial lipids does not result in resource competition with food production systems; is largely independent of environmental conditions; can be based on diverse substrates; and allows product composition to be customized based on the desired application $[3,4]$. As a result of recent advances in metabolic engineering and synthetic biology, it is now possible to produce a wide range of oleochemicals in both bacteria and yeast.

Unusual lipids differ from usual lipids in chain length (short, very long, and odd numbered), the position or number of double bonds (conjugated and polyunsaturated), and/or functional group type (e.g., hydroxy, epoxy, keto, branched chain, and cyclic) [5,6]. Unusual lipids can be highly valuable because they have applications in the pharmaceutical, food, and chemical industries. However, their low abundance in nature makes their mass production difficult. Consequently, using microbes to produce unusual lipids may serve as an environmentally sustainable and economically viable alternative $[3,7,8]$; for example, such lipids are naturally generated in a more finalized form because the need for chemical processes is reduced or avoided during manufacturing [3].

When it comes to the production of oleochemicals, oleaginous chassis display the clear advantage of accumulating larger quantities of lipids $(>20 \%$ of dry cell weight (DCW)). Yarrowia lipolytica, a well-studied oleaginous yeast, is considered to be a promising host because it utilizes a broad range of substrates, has efficient engineering toolkits, and is easy to cultivate at large scales [3,9]. Consequently, numerous studies have used metabolic engineering and the optimization of cultivation conditions to increase lipid titers, yield, and productivity in Y. lipolytica. To date, the focus has mainly been on usual 
lipids. Strains have been successfully engineered to produce more than $80 \mathrm{~g} / \mathrm{L}$ of lipids from a range of substrates [10-12]. More recently, interest has grown in producing unusual lipids, which are of high industrial value. This trend has been accompanied by the development of new synthetic biology tools and gene editing technology for Y. lipolytica $[13,14]$. Here, we review recent advances in the production of unusual lipids via metabolic engineering in this non-conventional yeast. We also briefly summarize the general dynamics of lipid metabolism and engineering strategies for lipid production in Y. lipolytica. Finally, we describe different approaches for producing specific unusual lipids, such as engineering the endogenous lipid synthesis system or introducing heterologous enzymes.

\section{Lipid Production in Yarrowia lipolytica}

Y. lipolytica is a well-characterized oleaginous yeast that displays a high flux of acetyl-CoA and an oil sequestration mechanism. The species' lipid metabolism has been thoroughly studied (Figure 1), and its lipid accumulation has been enhanced via engineering.

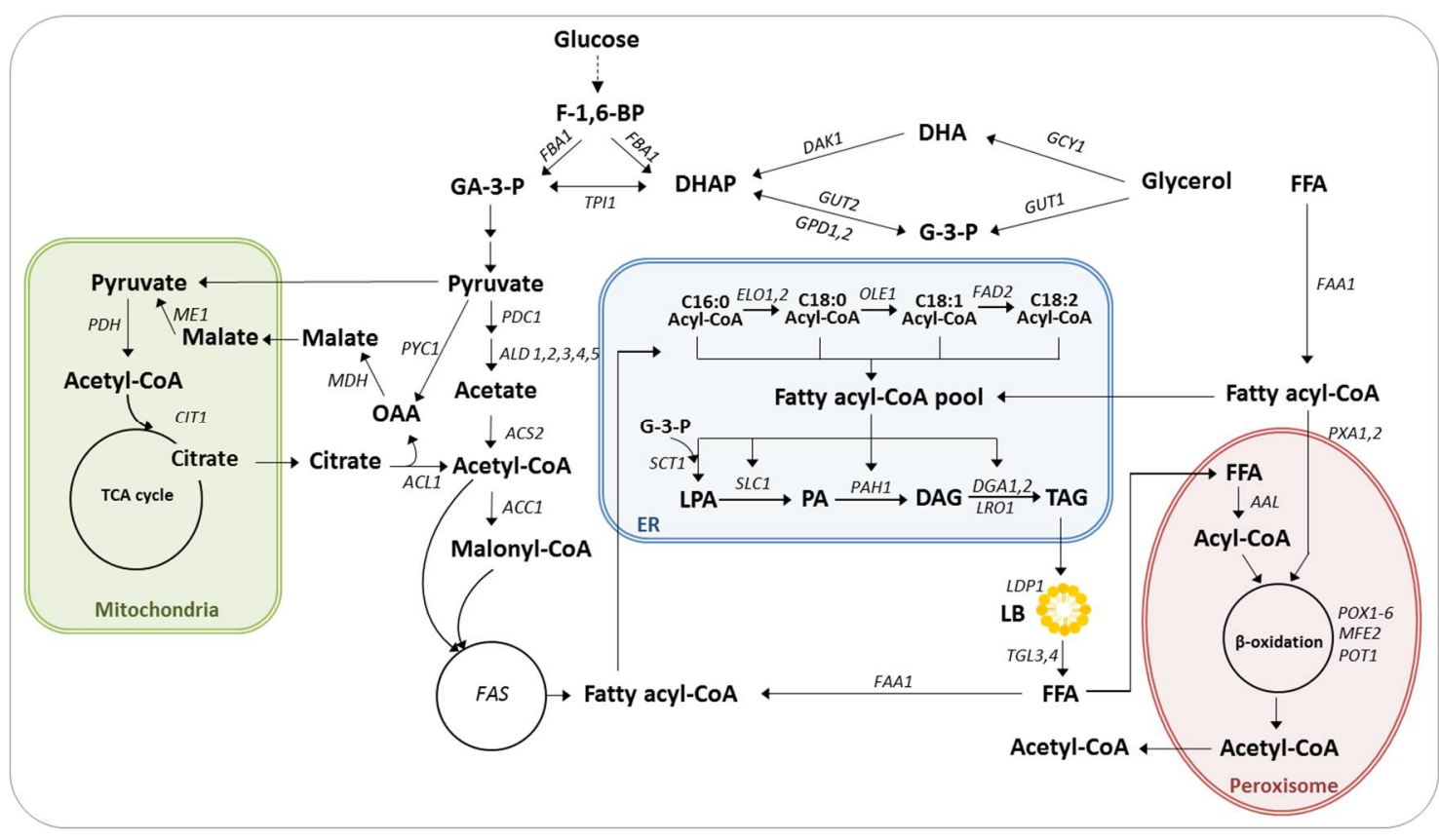

Figure 1. Lipid metabolism in Y. lipolytica. Abbreviations: F-1,6-BP, fructose-1,6-biphosphate; GA-3-P, glyceraldehyde-3-phosphate; DHAP, dihydroxyacetone phosphate; DHA, dihydroxyacetone; G-3-P, glycerol-3-phosphate; OAA, oxaloacetate; FFA, free fatty acid; LPA, lysophosphatidic acid; PA, phosphatidic acid; DAG, diacylglycerol; TAG, triacylglycerol; ER, endoplasmic reticulum; LB, lipid body; FBA1, fructose biphosphate aldolase; TPI1, triosephosphate isomerase; ME1, malic enzyme; PYC1, pyruvate carboxylase; $M D H$, malate dehydrogenase; $P D H$, pyruvate dehydrogenase; CIT1, citrate synthase; CTP1, citrate/malate transporter; $P D C 1$, pyruvate decarboxylase; ALD1-5, aldehyde dehydrogenase; ACS2, acetyl-CoA synthetase; $A C C 1$, acetyl-CoA carboxylase; FAS, fatty acid synthase; FAA1, fatty acyl-CoA synthetase; GPD1 and GPD2, glycerol-3-phosphate dehydrogenase; GUT1 and GUT2, glycerol kinase; DAK1, dihydroxyacetone kinase; GCY1, glycerol dehydrogenase; ELO1, 2, elongase; OLE1, $\triangle-9$ desaturase; FAD2, $\triangle$-12 desaturase; SCT1, glycerol-3-phosphate O-acyltransferase; SLC1, fatty acyl transferase; PAH1, phosphatidate phosphatase; DGA1, 2, DAG acyltransferase; LRO1, phospholipid:diacylglycerol acyltransferase; LDP1, lipid droplet protein; TGL3, 4, TAG lipase 3 and 4; $A A L$, acyl/aryl-CoA ligase; POX1-6, acyl-CoA oxidases 1-6; MFE2, peroxisomal multifunctional enzyme 2; POT1, 3-ketoacyl-CoA thiolase; LIP2,7, and 8, lipase; PXA1, 2, peroxisomal ATP-binding cassette transporter complex; dashed lines, multistep metabolic route. 


\subsection{Lipid Metabolism}

De novo fatty acid (FA) synthesis occurs in the cytosol. It begins with acetyl-CoA, which can arise from reactions mediated by acetyl-CoA synthetase (ACS, encoded by YALIOF05962g), pyruvate dehydrogenase complex (PDH), or ATP citrate lyase (ACL, encoded by YALIOE34793g and YALIOD24431g) [15]. Interestingly, $A C L$ genes are only present in the genomes of oleaginous yeast, as they are a hallmark of oleaginous microorganisms [16]. This acetyl-CoA is then converted into malonyl-CoA by acetyl-CoA carboxylase (Acc1, encoded by YALIOC11407g).

The fatty acid synthase (FAS) enzymatic complex (encoded by YALIOB15059g and YALI0B19382g) produces acyl-CoA by adding two carbons; acetyl-CoA serves as the initiation molecule, and malonyl-CoA serves as the elongation unit. The acyl-CoA molecules with chain length of 16 or 18 carbons are then transported into the endoplasmic reticulum (ER) for further elongation and desaturation by elongases (Elo1p encoded by YALIOF06754g and Elo2p encoded by YALIOB20196g) and desaturases (Ole1p; $\triangle 9$ desaturase encoded by YALI0C05951g and $\Delta 12$ desaturase; Fad2p encoded by YALIOB10153g) $[3,17,18]$.

The acyl-CoA products are part of a condensation reaction mediated by glycerol-3-phosphate (G3P). This process generates lysophosphatidic acid (LPA) via the action of G3P acyltransferase (Sct1p, encoded by YALIOC00209g), then phosphatidic acid (PA) via the action of LPA acyltransferase (Slc1p, encoded by YALIOE18964g), and finally diacylglycerol (DAG) via the action of phosphatidate phosphatase (Pah1p, encoded by YALIOD27016g). In the last step, DAG is converted into triacylglycerol (TAG) via the Kennedy pathway. This conversion process either involves phospholipids and the action of phospholipid:diacylglycerol acyltransferase (Lro1p, encoded by YALIOE16797g) or acyl-CoA and the action of DAG acyltranferases (Dga1p and Dga2p, encoded by YALIOE32769g and YALIOD07986g, respectively) $[19,20]$.

Y. lipolytica and other oleaginous yeasts mostly store their lipids as TAGs (80-90\% of the neutral lipid fraction); a smaller quantity are stored as steryl esters (SEs) in lipid bodies (LBs). Stored lipids are used as additional carbon sources under nutrient-limited environment through remobilization, transport, and degradation. TAGs are hydrolyzed to free fatty acids (FFAs) by two lipases: Tgl4p (encoded by YALIOF10010g), an active lipase found at the LB interface, and Tgl3p (encoded by YALI0D17534g), which is a positive regulator of Tg14p [21]. FFAs are then activated and transported to peroxisomes to be degraded. There are two possible routes: (1) FFAs can be activated by Faa1p in the cytoplasm and then transported to the peroxisome by the transporters Pxa1p/Pxa2p (encoded by YALI0A06655g/YALIOD04246g) or (2) they can be transported to the peroxisome and then activated by acyl/aryl-CoA-ligases (AALs) which required ATP provided by the ATP transporter Ant1p (encoded by YALIOE03058g) [22,23].

FA degradation takes place in the peroxisome via the $\beta$-oxidation pathway, which is a four-reaction cycle that shortens the FA backbone by two carbons and releases acetyl-CoA. In Y. lipolytica, the first step is carried out by six acyl-CoA oxidases encoded by POX genes (YALIOE32835g, YALIOF10857g, YALIOD24750g, YALIOE27654g, YALIOC23859g, and YALIOE06567g); these enzymes display different activity patterns depending on FFA chain length [24]. The second and third steps in $\beta$-oxidation are catalyzed by Mfe2p (a multifunctional enzyme encoded by YALIOE15378g). The fourth and last step in $\beta$-oxidation is carried out by Pot1p (a thiolase encoded by YALIOE18568g).

\subsection{Metabolic Engineering to Improve Lipid Production}

\subsubsection{Increasing the Size of Precursor Pools}

A common starting point in metabolic engineering is increasing the supply of precursors. In the case of FAs, these precursors are acetyl-CoA and malonyl-CoA. Y. lipolytica has the natural ability to produce high levels of cytosolic acetyl-CoA because of the yeast's ACL activity (Acl1p, Acl2p), which is particularly strong under conditions of nitrogen limitation. An attempt was made to decouple acetyl-CoA flux from nitrogen starvation by engineering several alternative cytosolic acetyl-CoA 
pathways, including the pyruvate-acetate route (mediated by pyruvate decarboxylase $p d c$, aldehyde dehydrogenase ald $\mathrm{H}$, and acetyl-CoA synthase acs); the pyruvate-aldehyde route (mediated by pyruvate decarboxylase $p d c$ and CoA-acetylating aldehyde dehydrogenase aad); the pyruvate formate lyase ( $p f l A$ and $p f l B$ ) and acetyl-CoA shuttling pathway (mediated by carnitine acetyltransferase cat2); and the non-oxidative pentose-phosphate pathway (mediated by phosphoketolase (PK) and phosphotransacetylase $p t a$ ) [25]. The overexpression of native $A C L$ only slightly increased lipid titers, as seen elsewhere [26]. Most of the other strategies, however, led to significant improvements. In particular, lipid titers improved by $75 \%$ when there was overexpression of the peroxisomal carnitine acetyltransferase (Cat2) taken from Saccharomyces cerevisiae, which enhanced the export of mitochondrial acetyl-CoA into the cytosol. Moreover, the engineered strain began accumulating lipids during the exponential growth phase before nitrogen became limiting. Using fed-batch cultivation, high lipid levels $(66.4 \mathrm{~g} / \mathrm{L})$ and oil content $(81.4 \%, \mathrm{~g} / \mathrm{g}$ DCW) were achieved, with an overall yield of $0.229 \mathrm{~g} / \mathrm{g}$ of glucose.

Several studies have shown that $A C C 1$ overexpression increases lipid accumulation by providing malonyl-CoA $[25,27,28]$. This strategy can increase lipid content two-fold, resulting in a greater representation of linoleic acid among total lipids [27]. In the same study, co-expression of $A C C 1$ and $D G A 1$ (the gene encoding DAG acyltransferase) significantly increased lipid content 4.7- and 2.3-fold compared to the control and the $A C C 1$-overexpressing strain, respectively. In a bioreactor, the strain overexpressing $A C C 1$ and DGA1 had a lipid content of $61.7 \%(\mathrm{~g} / \mathrm{g} \mathrm{DCW})$, and its overall yield and productivity from glucose were $0.195 \mathrm{~g} / \mathrm{g}$ and $0.143 \mathrm{~g} / \mathrm{L} / \mathrm{h}$, respectively. This simple but efficient method has shown that the push-and-pull strategy is extremely successful in enhancing lipid production.

The same group sought to overcome the potential allosteric inhibition of Acc1p by saturated FAs. To this end, they overexpressed delta-9 stearoyl-CoA desaturase (SCD, encoded by YALIOC05951g) to convert saturated FAs into monounsaturated FAs. The engineered strain had higher lipid titers $(55 \mathrm{~g} / \mathrm{L}$ from glucose), oil content $(67 \% \mathrm{~g} / \mathrm{g}$ DCW), overall yield $(0.234 \mathrm{~g} / \mathrm{g})$, and productivity $(0.707 \mathrm{~g} / \mathrm{L} / \mathrm{h})[28]$.

\subsubsection{Increasing Lipogenic Metabolic Flux}

Several studies have shown that diverting the carbon flux to TAGs can improve lipid production. The push-and-pull strategy described above (i.e., in which ACC1 and DGA1 are co-expressed) provides a good example of this approach [27]. Research has shown that Dga1p and Dga2p play an important role in boosting lipogenesis because they catalyze the last step in TAG synthesis $[19,27,29,30]$. The overexpression of these enzymes has successfully improved lipid production by influencing LB phenotype-DGA1 overexpression generates smaller but more numerous LBs, and DGA2 overexpression results in the formation of larger LBs [30]. Consequently, the strategy of enhancing the last step of TAG synthesis has generally been coupled with other engineering strategies.

Heterologous expression of DGA1 and DGA2 in Y. lipolytica has also been successfully used to engineer a lipid-overproducing phenotype. For instance, when DGA1 from Rhodosporidium toruloides and DGA2 from Claviceps purpurea were expressed in Y. lipolytica, they resulted in better performance than when their native equivalents were expressed [12]. The overexpression of these heterologous genes combined with the deletion of TGL3, which encodes the regulatory protein involved in TAG remobilization, resulted in a lipid content level of $77 \%(\mathrm{~g} / \mathrm{g}$ DCW) and a yield of $0.21 \mathrm{~g} / \mathrm{g}$ during batch cultivation. When a fed-batch process with glucose was used, the strain produced $85 \mathrm{~g} / \mathrm{L}$ of lipids and had a productivity level of $0.73 \mathrm{~g} / \mathrm{L} / \mathrm{h}$.

Another strategy can successfully improve lipid accumulation by redirecting carbon flux [31]. Because the G3P shuttle pathway provides the TAG backbone, it is closely tied to TAG synthesis. When G3P concentrations increase because of the overexpression of GPD1 and/or the deletion of GUT2, TAG synthesis also increases. Further engineering that couples $\beta$-oxidation inactivation and GPD1 overexpression leads to tandem increases in G3P concentrations and FA availability, resulting in more pronounced lipid accumulation (up to $65 \% \mathrm{~g} / \mathrm{g} \mathrm{DCW}$ ). 


\subsubsection{Inhibiting Lipid Remobilization and Degradation}

TAGs stored in LBs are transported to the peroxisome and degraded by $\beta$-oxidation. These processes are part of an antagonistic pathway leading to lipid synthesis and accumulation. Therefore, the genes involved in lipid transport and degradation are useful deletion targets in efforts to improve lipid production.

It is known that intracellular lipases encoded by TGL3 and TGL4 are involved in TAG remobilization. In Y. lipolytica, the inactivation of Tgl3p and/or Tgl4p led to higher levels of lipid accumulation-amounts of TAGs and FFAs increased, but FA profiles were unaffected [21]; furthermore, Tgl4p was found to be a major intracellular lipase that was activated by Tgl3p. Lipid accumulation was boosted by both deleting TGL3 and overexpressing heterologous DGA1 and DGA2 in Y. lipolytica [12].

When the $\beta$-oxidation pathway was inhibited via the inactivation of $P O X$ genes, greater lipid accumulation occurred. The deletion of the POX1-6 genes combined with GUT2 deletion resulted in a 3.2-fold increase in lipid content (from $12.76 \%$ to $41.92 \%, \mathrm{~g} / \mathrm{g}$ DCW); the engineered strain exhibited a hyper lipid-accumulating phenotype with extremely large LBs [32]. When $\beta$-oxidation was knocked out and both DGA2 and GPD1 were overexpressed, lipid accumulation levels reached 55\% (g/g DCW) under nitrogen-limited conditions [33,34].

It has been shown that inactivating MFE, which catalyzes the second and the third step in $\beta$-oxidation, can also improve lipid accumulation. Moreover, the deletion of GUT2, POX1-6, and MFE1 combined with the overexpression of GPD1 was also found to drive higher levels of lipid accumulation (65-75\% g/g DCW) [31].

Another strategy for increasing lipid accumulation has been to allow $\beta$-oxidation but to disrupt peroxisome biogenesis, notably by deleting the genes PEX3, PEX10, and PEX11 [35,36]. A 60-fold increase in lipid titers $(25 \mathrm{~g} / \mathrm{L})$ and a lipid content of nearly $90 \%(\mathrm{~g} / \mathrm{g} \mathrm{DCW})$ were obtained by combining the deletion of PEX10 and MFE2 with the overexpression of DGA1 [29]. This engineered strain was used for an evolutionary approach with a floating cell enrichment process, enhanced lipid titers of up to $39.1 \mathrm{~g} / \mathrm{L}$ and a lipid content of $77.6 \%$ (g/g DCW) were achieved [37].

\subsubsection{Engineering Redox Metabolism}

In lipid synthesis, a crucial variable is the availability of the FAS cofactor, NADPH, which converts acetyl groups into fully reduced acyl chains. Traditionally, the cytosolic NADP ${ }^{+}$-dependent malic enzyme is thought to be the major producer of lipogenic NADPH and to operate via a trans hydrogenation mechanism termed the pyruvate-oxaloacetate-malate (POM) cycle [38,39]. However, in Y. lipolytica, a malic enzyme is predicted to be found in the mitochondria, which is inconsistent with what is known for other oleaginous yeasts. Further, in the same species, the overexpression of the native malic enzyme did not increase lipid production, and the enzyme had a greater affinity for $\mathrm{NAD}^{+}$ than for $\mathrm{NADP}^{+}[16,40]$.

Many studies have suggested that $Y$. lipolytica regenerates NADPH almost exclusively through the oxidative pentose phosphate pathway (oxPPP) [41]. As determined by ${ }^{13} \mathrm{C}$ metabolic flux analysis, flux through the oxPPP was significantly enhanced in an engineered strain overexpressing DGA1 and ACC1. Furthermore, the estimated rate of NADPH synthesis via the oxPPP was consistent with the estimated rate of NADPH consumption in the TAG synthesis pathway in engineered strains. This idea has received additional support from research in which the overexpression of related enzymes enhanced the flux through the oxPPP and increased lipid synthesis [42-44]. For example, Dobrowolsk and Mirończuk investigated each gene of the PPP, the overexpression of transketolase (TKL1, YALI0E06479g) in DGA1-overexpressed strain showed the increase of lipid content and titer $(23.94 \%$ (g/g DCW), $1.42 \mathrm{~g} / \mathrm{L}$ ) over the control strain $(16.89 \%$ (g/g DCW), $0.83 \mathrm{~g} / \mathrm{L})$ with glycerol as a sole carbon source [44]. In another study, an analysis of the metabolic network during lipid production revealed an imbalance in electron cofactors-NADH was present in excess, whereas NADPH was limiting [11]. To convert the excess NADH into NADPH and thus enhance lipid production, several pathway modules were constructed [11]. Two NADP ${ }^{+}$-dependent glyceraldehyde-3-phosphate dehydrogenase genes (GapC 
from Clostridium acetobutylicum and GPD1 from Kluyveromyces lactis) were overexpressed in a strain with an ACC1- and DGA1-overexpressing background; lipid accumulation improved by $20 \%$ and $17.8 \%$, respectively. Research was also performed to determine whether a cytosolic $\mathrm{NADP}^{+}$-dependent malic enzyme, Mce2p from Mucor circinelloides, could activate the POM cycle and further boost the conversion of NADH to NADPH. The introduction of Mce2p improved yield by $23 \%$. When GapC introduction was coupled with YEF (endogenous NAD ${ }^{+} / \mathrm{NADH}$ kinase) overexpression, the result was multiple functional synthetic pathways working simultaneously to convert NADH to NADPH. In the final engineered strain, lipid titers, productivity, and yield reached $99 \mathrm{~g} / \mathrm{L}, 1.2 \mathrm{~g} / \mathrm{L} / \mathrm{h}$, and $0.27 \mathrm{~g} / \mathrm{g}$, respectively.

\subsubsection{Removing Competing Byproducts}

In addition to TAG, glycogen can also store excess carbon. Glycogen starts to accumulate only after the complete depletion of the nitrogen source, which is the same pattern as seen with TAG accumulation. Therefore, research examined whether redirecting carbon flux from glycogen synthesis to TAG synthesis could improve lipid accumulation [45]. It was found that glycogen could account for up to $16 \%$ of biomass in wild-type (WT) Y. lipolytica (strain W29). In a strain in which the gene for glycogen synthase (Gsy1p, encoded by YALI0F18502g) had been deleted, TAG accumulation was $60 \%$ higher than in the WT strain. TAG accumulation increased even further, from $44.9 \%$ to $52.4 \%(\mathrm{~g} / \mathrm{g}$ DCW), when TGL4 was also deleted and DGA2 and GPD1 were overexpressed.

\section{Unusual Lipids: Fatty Acids with Tailored Chain Lengths}

One of the advantages of microbial lipid production is that lipid profiles can be customized to suit industrial applications. Lipids with unusual chain lengths are increasingly the target of metabolic engineering because they are rare in nature, they have numerous applications, and they are economically valuable.

The TAG oil naturally produced by $Y$. lipolytica is mainly composed of long-chain FAs, palmitic acid (C16:0), palmitoleic acid (C16:1 $\Delta 9)$, stearic acid (C18:0), oleic acid (C18:1 $\Delta 9)$, and linoleic acid (C18:2 $\Delta 9 \Delta 12)$. Studies that have successfully synthesized FAs with specific chain lengths, such as medium-chain FAs (MCFAs), odd-chain FAs (OCFAs), and very-long-chain FAs (VLCFAs) are described in this section and in Table 1.

\subsection{Medium-Chain Fatty Acids}

MCFAs (chain length range: $\mathrm{C} 6-\mathrm{C} 12)$ are valuable compounds in the chemical industry. They can be used as biofuels as well as intermediate fine chemicals for generating plastics, surfactants, biocontrol agents, and cosmetics [46,47]. Since MCFAs are present in very low concentrations in only a few seed oils (i.e., coconut and palm kernel oils), an alternative source of MCFAs could be microbial production utilizing renewable biomass, which would be a more environmentally sustainable and economically feasible approach $[47,48]$. Because FA chain length is associated with the termination of the elongation cycle during FA synthesis, research has been performed on thioesterases that have a specificity for MCFAs [49,50]. Furthermore, biochemical and structural analyses have been carried out to characterize the FAS elongation mechanism with a view to modifying FA chain length [51-53].

In Y. lipolytica, the heterologous acyl-ACP thioesterases (ACPTs) from plants and bacteria can terminate elongation early to produce MCFAs, namely decanoic acid (C10-FA) or octanoic acid (C8-FA) [54]. Among the five heterologous ACPTs tested, four resulted in the production of C10-FA (representing 36-57\% of total lipids). The strain expressing ACPT from Umbellularia californica produced the highest ratio of C8-FA (14\% of total lipids). The MCFAs produced were found to represent all the different lipid classes, including TAGs, DAGs, MAGs, sterols, steryl esters, and FFAs. This finding indicates that the enzymes were successfully incorporated into the native machinery. Plant, fungal, and bacterial fatty ACPTs were also screened to determine whether they displayed distinct chain-length specificities when producing MCFAs [25]. In Y. lipolytica, the expression of fatB2 from Cocos nucifera 
resulted in the production of C12-FA (2.3\% of total lipids), and the expression of $y b g \mathrm{C}$ from Escherichia coli resulted in the production of C14-FA (up to $19.2 \%$ of total lipids). An attempt was made to further increase MCFA levels by introducing the bifunctional acyl-ACP/acyl-CoA thioesterase from E. coli (EcTesA). To bridge the gap in substrate specificity between native FAS and thioesterase, the malonyl/palmitoyl transacylase (MPT) domain of the native FASI was substituted with a truncated FAS1 fused with thioesterases (hFAS-TEs). The hybrid hFAS-TEs increased C12-FA and C14-FA production. For example, the strain expressing hFAS-EcTesA' (truncated EcTesA) displayed a boost in C14-FA levels (up to $29.2 \%$ of total lipids).

A mutation was introduced into the native FAS system of Y. lipolytica to determine the effects on MCFA production [55]. It was hypothesized that ketoacyl synthase (the KS domain in Fas1p) catalyzes the condensation reaction between acyl-ACP and malonyl-CoA and thus determines chain length during the production of long-chain FAs (C16 and C18). The FA binding site (Ile1220) in the KS domain, as predicted via molecular modeling, was replaced with various amino acid residues. MCFAs (mostly C14-FA) were produced when the binding site was replaced by an aromatic amino acid. The best performing mutant, I1220W, accumulated C14-FA at levels representing $11.6 \%$ in total FAs. The I1220W strain underwent additional engineering to further improve C14-FA accumulation [56]: to inhibit the elongation of C14-FA and C16-FA, ELO1 was deleted. As a result, C14-FA was the predominant compound produced by the mutant ( $87 \%$ of total lipids). Heterologous diglyceride acyltransferase (DGAT) from Elaeis guineensus was also introduced to boost the accumulation of MCFAs in the form of TAGs. C14-FA content reached $1.25 \mathrm{~g} / \mathrm{L}$, which is 1.7 times higher than the amount seen in the control strain.

\subsection{Odd-Chain Fatty Acids}

OCFAs represent less than 3\% of the total FAs naturally synthesized by microorganisms, plants, and animals. However, they have various important industrial applications. For example, cis-9-heptadecenoic acid (C17:1) has anti-inflammatory properties and can help treat psoriasis, allergies, and autoimmune diseases when used in pharmaceuticals or cosmetics [57]. In the chemical industry, cis-9-heptadecenoic acid is used as a biocontrol agent in the fight against powdery mildew, a fungal disease that affects a wide range of plants [58]. In addition, OCFAs and their derivatives are precursors for manufacturing flavor and fragrance compounds, hydraulic fluids, plasticizers, coatings, and other industrial substances [58-61].

The synthesis of OCFAs diverges from that of ECFAs during the first cycle of FA elongation: propionyl-CoA merges with malonyl-CoA instead of with acetyl-CoA [62]. To provide a source of propionyl-CoA, it is common to utilize compounds with three-carbon chains, such as propionate, propionic acid, or 1-propanol.

Previous work in E. coli found that OCFA production could be improved via metabolic engineering strategies and propionate supplementation [63]. One strategy was to introduce the propionyl-CoA synthetase gene (SeprpE) from Salmonella enterica to increase intracellular propionyl-CoA availability resulting from propionate supplementation. Another was to switch out the native $\beta$-ketoacyl-ACP synthase III (encoded by $f a b H$ ) with BsFabH1 from Bacillus subtilis to enhance propionyl-CoA specificity. The final strain overexpressed SeprpE and SafabH and produced $1.205 \mathrm{~g} / \mathrm{L}$ of OCFAs $(60.25 \%$ of total lipids), with C15-FA predominating.

Several studies have shown that, in Y. lipolytica, the WT strain can use propionate to produce high levels of OCFAs (up to $43 \%$ of total lipids) [64,65]. When propionyl-CoA catabolism was inhibited, the representation of OCFAs among total lipids climbed from $28.3 \%$ to $46.8 \%$ [66]. Y. lipolytica was further engineered ( $m f e 1 \Delta \operatorname{tgl} 14 \Delta$ TEF-GPD1 pTEF-DGA2) to accumulate large amounts of lipids, increasing both OCFA levels and total lipid content; the final strain produced $0.75 \mathrm{~g} / \mathrm{L}$ of OCFAs, mainly C17:1-FA, thanks to an optimized fed-batch co-feeding strategy [66]. This strain was further modified to boost propionyl-CoA pools by screening for propionate-activating enzymes [67]. The highest levels of OCFA production (3.8 times higher than those in the control strain) were obtained by expressing 
propionyl-CoA transferase (PCT) from Ralstonia eutropha. To further increase OCFA production, pools of $\beta$-ketovaleryl-CoA were bolstered by introducing $\beta$-ketothiolase (BktB) from R. eutropha. The final strain produced $1.87 \mathrm{~g} / \mathrm{L}$ of OCFAs, which accounted for $62 \%$ of total lipids $(\mathrm{C} / \mathrm{N}$ ratio $=45)$.

Glucose has also been used to drive the endogenous synthesis of propionyl-CoA and OCFA production in Y. lipolytica [68]. Overexpression of the aspartate/ $\alpha$-ketobutyrate pathway increased the representation of OCFAs among total lipids from $0.84 \%$ to $3.86 \%$. When this strategy was combined with the high lipid-accumulation strategy, glucose-based OCFA production improved 7.2-fold, reaching $0.36 \mathrm{~g} / \mathrm{L}$ when flask cultivation was used.

\subsection{Very-Long-Chain Fatty Acids}

Very-long-chain fatty acids (VLCFAs; C22-C26) are essential biological compounds that occur in small quantities among cellular lipids. VLCFAs are intermediate molecules in reactions that generate very-long-chain fatty alcohols (e.g., docosanol) and very-long-chain fatty waxes (e.g., Jojoba oil), which are widely used as lubricants, detergents, polymers, developing agents for photographic film, cosmetics, and pharmaceuticals [69-73].

Elongases that act on FA chain lengths have become targets in efforts to increase VLCFA production because they display different substrate specificity depending on their origin. For example, in S. cerevisiae, the endogenous FA elongation system (scELO1, scELO2, and scELO3) was engineered and the FASI system from Mycobacterium vaccae was introduced to enhance the production of VLCFAs ranging in chain length from $\mathrm{C} 22$ to $\mathrm{C} 26$ [72].

In Y. lipolytica, C20-C22 VLCFAs were synthesized by overexpressing $\beta$-ketoacyl-CoA synthases (KCSs) from Arabidopsis thaliana that convert C16 and C18 LCFAs into VLCFAs [74]. VLCFA production was increased three-fold by deleting the peroxisome biogenic gene, PEX10, and thus inhibiting LCFA-CoA catabolism. The strain was further engineered by introducing the $\mathrm{C} 16 / \mathrm{C} 18$-elongase from Mortierella alpina (MaELO3) and KCS from Crambe abyssinica, which boosted levels of C22-24 VLCFAs. To increase quantities of acetyl-CoA, a key FA precursor, aldehyde dehydrogenase (ALDH) from E. coli was overexpressed; the result was a 1.7-fold increase in VLCFA titers $(280 \mathrm{mg} / \mathrm{L})$. The strain was also engineered to produce VLCFA derivatives, fatty alcohols, and wax esters by screening for heterologous enzymes-FA reductases (FARs) and wax ester synthases (WSs).

Erucic acid (C22:1 $\Delta 13)$ is a VLCFA with a variety of uses. For example, it can be employed to create lubricants, surfactants, and biodiesels. In nature, it is produced by a small number of plants. However, a Y. lipolytica strain was recently engineered to generate erucic acid [73]. The process involved inhibiting the desaturation of $C 18: 1$ by deleting FAD2 ( $\triangle 12$ desaturase), which improved the availability of erucic acid's precursor (C18:1). Additionally, FAE1 from Thlaspi arvense (TaFAE1) was overexpressed to synthesize VLCFAs (C20-C24). In the engineered strain, levels of erucic acid increased to represent $6 \%$ of total FAs; levels of arachidic acid (C20:0) and gondoic acid (C20:1 $\Delta 11)$ also significantly increased. VLCFA production dynamics were compared for different concentrations of two carbon sources, glycerol and waste cooking oil. For the final strain, yield was the greatest $(887 \mathrm{mg} / \mathrm{L})$ when using waste cooking oil $(6 \% \mathrm{w} / \mathrm{v})$.

\section{Unusual Lipids: Fatty Acid Derivatives}

Both FAs and their derivatives are compounds of interest for biotechnological applications. Depending on the enzymes introduced, a broad range of FA derivatives can be generated. For example, FFAs can be created with thioesterase, FA ethyl esters (FAEEs) with ester synthase, FA methyl esters (FAMEs) with methyl transferase, and fatty alcohols with FA reductase, just to cite a few possibilities. Some attractive FA derivatives that can be produced in Y. lipolytica are discussed in this section and illustrated in Figure 2. 


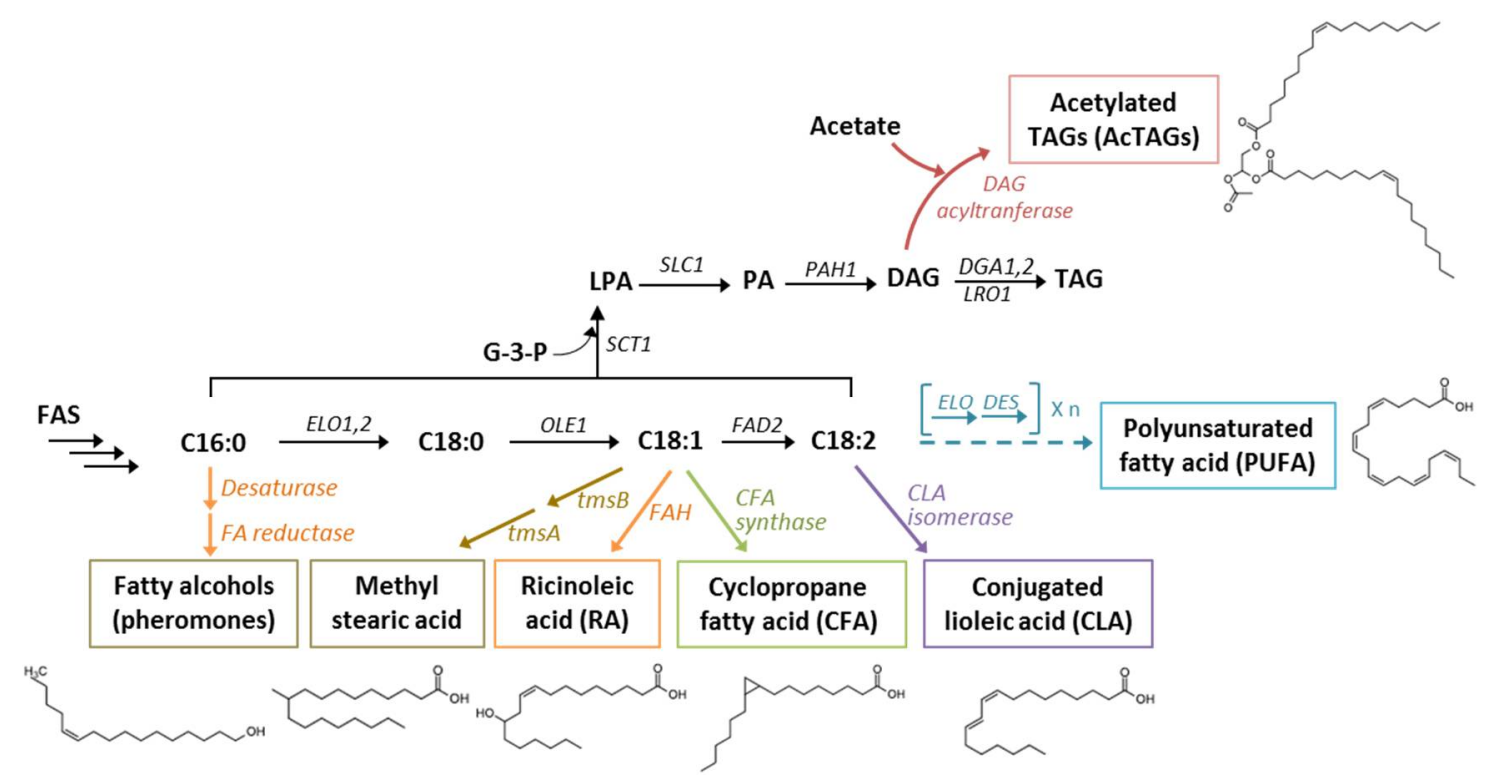

Figure 2. Fatty Acid (FA) derivatives that can be produced in Y. lipolytica. FA derivatives of interest are enclosed in colored boxes, and heterologous reactions are indicated with colored arrows. Abbreviations: AcTAGs, acetylated TAGs; FA, fatty acid; RA, ricinoleic acid; CFA, cyclopropane fatty acid; CLA, conjugated linoleic acid; FAS, fatty acid synthase; ELO1,2, elongase 1,2; OLE1, $\triangle 9$ desaturase; FAD2, $\triangle 12$ desaturase; SCT1, glycerol-3-phosphate O-acyltransferase; SLC1, fatty acyl transferase; PAH1, phosphatidate phosphatase; DGA1,2, DAG acyltransferase; LRO1, phospholipid:diacylglycerol acyltransferase; tmsB, methyltransferase; tmsA, reductase; $F A H, \triangle 12$-oleate hydroxylase; $E L O$, elongase; $D E S$, desaturase.

\subsection{Conjugated Linoleic Acids}

Conjugated linoleic acids (CLAs) are the isomers of linoleic acid (C18:2, $n=9,12)$. CLAs can be used to prevent metabolic diseases and cancer, combat atherogenesis and obesity, and modulate the immune system [75]. Consequently, the production of CLAs is of interest to the food and pharmaceutical industries. Attempts have been made to generate recombinant CLAs in Lactobacillus planetarium, Delacroixia coronate, S. cerevisiae, and various plant species [76-78].

In Y. lipolytica, an increase in CLA production (5.9\% of total lipids) was obtained by expressing a large number of gene copies encoding CLA-producing isomerase from Propionibacterium acnes (PAI) [79]. For the best-performing strain, the rate for converting linoleic acid (LA) to CLAs was $80 \%$ under biotransformation conditions. The strain was further engineered to co-express CLA-producing isomerase and FAD2 from Mortierella alpine from multiple gene copies, such that CLAs represented up to $0.4 \%$ of DCW and $10 \%$ of total FAs [80]. When grown with soybean oil-based media, the strain's CLA production ramped up dramatically ( $30 \%$ of DCW and $44 \%$ of total FAs). CLA titers reached $4 \mathrm{~g} / \mathrm{L}$, including the $0.9 \mathrm{~g} / \mathrm{L}$ in the growth medium.

Another metabolic engineering approach was recently used to boost CLA production in $Y$. lipolytica [81]. It focused on blocking $\beta$-oxidation and TAG storage and overexpressing native FAD2 and the CLA-producing isomerase (PAI) from P. acnes. When flask cultivation was employed, CLAs represented up to $6.5 \%$ of total FAs; when bioreactor was used, CLA titers reached $302 \mathrm{mg} / \mathrm{L}$. Other research successfully produced trans-10-cis-12-CLA in Y. lipolytica by introducing FAD2 from M. alpine and the same isomerase (PAI) from P. acnes [82]. CLA production improved to $132.6 \mathrm{mg} / \mathrm{L}$ when the additional steps were taken of overexpressing DGA1, optimizing culture conditions (i.e., carbon and nitrogen sources, carbon-to-nitrogen mass ratio, and $\mathrm{CaCl}_{2}$ content), and using glycerol as the sole carbon source [82]. 


\subsection{Cyclopropane Fatty Acids}

Easily converted to methylated FAs, cyclopropane fatty acids (CFAs) have applications in the lubrication and oleochemical industries because of their long-term resistance to oxidization and their fluidity at low temperatures [83-85]. CFAs are naturally produced in a variety of different organisms, ranging from bacteria to plants, and can represent varying percentages of total FAs (as high as $46 \%$ ) [86]. During natural production processes, CFAs typically accumulate in membrane-bound phospholipids. Consequently, strategies were developed for Y. lipolytica to produce CFAs in the form of TAGs, which serve as a more desirable production pool [86,87].

CFA synthase from E. coli was overexpressed in a Y. lipolytica strain that had been engineered to accumulate large amounts of lipids by disrupting $\beta$-oxidation and overexpressing $D G A 1$; using flask cultivation, $190 \mathrm{mg} / \mathrm{L}$ of C19CP (C19:0 cyclopropane) was produced. When fed-batch fermentation was employed, C19CP titers reached $3.03 \mathrm{~g} / \mathrm{L}$ (representing 32.7\% of total FAs) [86].

Alternative research took the approach of assessing how 10 CFA synthase-coding genes from different organisms affected CFA production in Y. lipolytica [87]. However, instead of employing the technique described above [86], the objective was to test different hybrid promoters with a view to finding the optimal promoter for producing CFAs. In the final strain, TAG degradation and remobilization were blocked, and CFA synthase from E. coli was overexpressed under the strong Hp8d promoter; this strain produced $2.32 \mathrm{~g} / \mathrm{L}$ of CFAs (representing $45.8 \%$ of total FAs) [87]. Imatoukene and colleagues introduced E. coli CFA synthase into Y. lipolytica which was metabolically engineered to accumulate high amount of fatty acid and phospholipid remodeling [88]. The optimization of bioprocess strategy resulted in $70 \%$ (g/g DCW) of lipid accumulation, $7.49 \mathrm{~g} / \mathrm{L}$ of CFA, and with a CFA productivity of $103.3 \mathrm{mg} / \mathrm{L} / \mathrm{h}$.

\subsection{Ricinoleic Acid}

Ricinoleic acid (RA) is a hydroxylated FA (12-hydroxy-octadeca-cis-9-enoic acid, C18:1-OH) that can be used as a substrate for double-bond and hydroxyl-group reactions or as an intermediate compound in reactions generating plasticizers, lubricants, dyes, inks, soaps, pharmaceuticals, food additives, cosmetics, and biofuels, among other products [89-91]. Recombinant production of RA was attempted using plants, but the resulting RA levels were lower than those seen in a native producer-castor seeds [91-94]. Microbial production of RA was explored using S. cerevisiae, Schizosaccharomyces pombe, and Pichia pastoris [92,95-97]. When FAH12 ( $\triangle 12$-oleate hydroxylase) from C. purpurea was overexpressed in S. pombe, RA titers reached $137.4 \mathrm{mg} / \mathrm{L}$ (representing $52.6 \%$ of total FAs) [95]. To reduce the toxicity of RA, intracellular phospholipase (PTL2) was overexpressed, which increased RA secretion and intracellular levels 1.2 and 1.3-fold, respectively [96]. In P. pastoris, co-expression of C $p F A H$ and CpDGAT1 from C. purpurea resulted RA titers of $495 \mathrm{mg} / \mathrm{L}$ [97].

A Y. lipolytica strain was engineered in multiple ways to accumulate large amounts of RA (up to $43 \%$ of total lipids; more than $60 \mathrm{mg} / \mathrm{g}$ DCW) [98]. To provide the substrate for RA production, $\beta$-oxidation was blocked, and the FAD2 gene was deleted. By deleting three DAG acyltransferases and overexpressing LRO1, TAGs were exclusively synthesized through the phospholipid pathway. When the strain also overexpressed FAH12 from C. purpurea, RA titers reached $12 \mathrm{~g} / \mathrm{L}$ (representing $60 \%$ of total lipids) in a bioreactor. Recently, secondary structure prediction and mutagenesis helped identify the crucial domain involved in CpFAH12 hydroxylation in Y. lipolytica [99] and a consolidated RA production process was developed by introducing RA synthesis in a strain engineered for cellulose utilization [100].

\subsection{Polyunsaturated Fatty Acids}

Polyunsaturated fatty acids (PUFAs) have attracted scientific attention because of their numerous health benefits. Of particular note are eicosapentaenoic acid (EPA, 20:5, n-3) and docosahexaenoic acid (DHA, 22:6, n-3), which are also known as long-chain omega-3 FAs. They reduce the incidence of 
cardiovascular diseases and prevent myocardial infarction, bronchial asthma, inflammatory bowel disease, severe depression, and several types of cancer [101]. Fish oils are the natural source of omega-3 FAs, but concerns about overfishing and pollution in marine ecosystems have led to researchers to attempt to microbially produce EPA and DHA [102,103]. A few products generated by microalgae (Crypthecodinium cohnii and Schizochytrium species) are commercially available [103-105]. EPA has been successfully produced in Y. lipolytica via a metabolic engineering strategy that introduced $\Delta 6$ desaturase, C18/20 elongase, $\Delta 5$ desaturase, and $\Delta 17$ desaturase. The strain was further engineered to overexpress an elongase from $M$. alpina and a $\Delta 12$ desaturase from Fusarium moniliforme, resulting in high levels of EPA (40\% of total lipids) [101,104,105]. EPA production was improved even more by eliminating a competitive pathway that generated byproducts and by introducing multiple copies of genes encoding crucial enzymes (described above); the final strain produced levels of EPA that accounted for approximately $21.3 \%$ of DCW and 57\% of FAMEs [106]. This strategy has led to commercial products-New Harvest ${ }^{\mathrm{TM}}$ EPA oil and Verlasso ${ }^{\circledR}$ salmon-and illustrates the successful use of Y. lipolytica as a chassis for biotechnological applications [3]. Recently, transgenic Y. lipolytica strains were created that produce specific PUFAs, such as arachidonic acid (AA, 20:4, n-6), EPA, docosapentaenoic acid (DPA, 22:5, n-3), and DHA [107]. The multifunctional polyketide synthase (PKS)-like PUFA synthases from Aetherobacter fasciculatus and Minicystis rosea were introduced in a diverse hybrid form to Y. lipolytica and have been employed to produce mainly DHA and AA, respectively. Under conditions of improved fermentation, the engineered strain had DHA titers of 350 $\mathrm{mg} / \mathrm{L}$ (representing $16.8 \%$ of total FAs).

\subsection{Emerging Target Compounds}

\subsubsection{Acetylated Triacylglycerols}

Structurally, 3-acetyl-1,2-diacylglycerols (acTAGs) are similar to regular TAGs. However, the two groups differ at the $s n-3$ position, which is esterified by an acetate rather than by an FA [108]. The acTAGs are naturally found in plants of the family Celastraceae and in animals like Cerous nippon and Eurosta solidaginis. Because of their acetyl moiety, acTAGs have lower viscosity and calorific value than TAGs, which are characteristics of value in certain industrial products, like biodiesels, emulsifiers, lubricants, and plasticizers. When heterologous diacylglycerol acetyltransferase (DAcT) from Eunonymus europaeus was introduced into a Y. lipolytica WT strain, acTAGs represented about $20 \%$ of total lipids [108]; when DAcT was overexpressed in a non-TAG-accumulating strain, acTAGs (representing $10 \%$ of total lipids) were the only stored lipid.

\subsubsection{Methylated Fatty Acids}

Saturated branched (methyl) lipids like 10-methylstearic acid have desirable properties, such as fluidity at low temperatures and oxidative stability. These characteristics are useful when the compounds are employed in lubricants and specialty fluids. Oleic acid and methionine can serve as substrates that are converted into 10-methylenestearic acid by methyltransferase (tmsB) and then further transformed into 10-methylstearic acid by reductase (tmsA). A relatively recent study explored the effects of co-expressing $t m s B$ and $t m s A$ of different origins in several microorganisms, including $Y$. lipolytica [109]. It was found that the co-expression of $t m s A$ and $t m s B$ from Thermomonospora curvata could produce branched 10-methyl and 10-methylene FAs in Y. lipolytica. Fusion enzymes (tmsA-B), which displayed the activities of both enzymes, allowed 10-methylstearic acid to be produced (at levels representing more than $20 \%$ of total FAs).

\subsubsection{Pheromones (Fatty Alcohols)}

In pest control efforts, insect sex pheromones can be used as an alternative to insecticides, which have adverse effects on human health and the environment. Consequently, the biotechnological production of pheromones has recently begun to draw interest. 
The sex pheromones of moth pests, (Z)-hexadec-11-en-1-ol (Z11-16OH) and (Z)-tetradec-9-en-1-ol (Z9-14OH), have been produced in Y. lipolytica by introducing a desaturase from Amyelois transitella (AtrD11) and a reductase from Helicoverpa armigera (HarFAR) [110]. To improve pheromone production, fatty alcohol degradation was inhibited ( $h f d 1-4 \Delta f a 01 \Delta)$, and the size of the precursor pool was boosted by inhibiting FA degradation and storage (pex10 $\Delta$, truncated pGPAT). The final strain contained multiple copies of the genes encoding the desaturase and reductase. When grown in a bioreactor, it produced $\mathrm{Z} 11-16 \mathrm{OH}$ titers of $2.6 \mathrm{~g} / \mathrm{L}$. The efficiency and specificity of these pheromones were verified by successfully trapping male $H$. armigera moths in a cotton field.

Bumble bee pheromones were synthesized in Y. lipolytica by overexpressing fatty acyl-CoA reductases: BlapFAR4 from Bombus lapidaries and BlucFAR1 from Bombus lucorum [111]. Each enzyme displayed a different substrate preference. BlapFAR4 overexpression produced mostly $\mathrm{C} 16: 0-\mathrm{OH}$ and $\mathrm{C} 16: 1 \triangle^{9}-\mathrm{OH}$, while BlucFAR1 overexpression produced a mixture of saturated fatty alcohols (C18-C24). The highest fatty alcohol titers $(166.6 \mathrm{mg} / \mathrm{L})$ were obtained by overexpressing BlucFAR1 in a strain that accumulated large amounts of lipids.

\section{Conclusions and Perspectives}

Y. lipolytica is a promising host for producing lipid-based chemicals. Great strides have been made in using this non-conventional yeast, thanks to extensive research into lipid metabolism and the development of metabolic engineering tools. The deployment of genetic tools and metabolic models has further accelerated improvements in oleochemical production in this yeast. Unusual lipids are targets of particular interest because of their diverse applications. Native producers of unusual lipids are rare, making large-scale production challenging. Consequently, using microbes as factories for generating unusual lipids should be a more economically feasible and environmentally sustainable approach. This review discussed the diverse unusual lipids that have been produced in Y. lipolytica via metabolic engineering. However, most of the research described involves production at the laboratory scale or proof-of-concept studies. It is hoped that combining metabolic engineering strategies and systems biology will help identify the rate-limiting steps present in the processes used to generate unusual lipids, thus boosting their production. The range of potential unusual lipids can be broadened by identifying novel enzymes via system metabolic engineering. Additionally, to permit production at industrial scales, it will be necessary to optimize fermentation processes, maximize yield, and reduce the formation of byproducts. Production costs can be reduced by utilizing cheap raw materials, a topic that has already been extensively studied in Y. lipolytica. By addressing this suite of issues, the microbial production of unusual lipids will move much closer to becoming commercially viable. 
Table 1. The production of unusual lipids via metabolic engineering in Y. lipolytica.

\begin{tabular}{|c|c|c|c|c|c|}
\hline Product & Strain Genotype & Strategy & Production Details & $\%$ of Total Lipids & Reference \\
\hline MCFA & po1f $p T E F-U c A C P T$ & $\begin{array}{c}\text { Introduction of heterologous acyl-ACP } \\
\text { thioesterases }\end{array}$ & C8-FA & 14 & {$[54]$} \\
\hline MCFA & po1f $p T E F-C p a A C P T$ & $\begin{array}{c}\text { Introduction of heterologous acyl-ACP } \\
\text { thioesterases }\end{array}$ & C10-FA & 57 & [54] \\
\hline MCFA & po1g $h F A S-E c T e s A^{\prime 1}$ & $\begin{array}{c}\text { Introduction of heterologous acyl-ACP } \\
\text { thioesterases and hybrid fatty acid } \\
\text { synthase-thioesterase }\end{array}$ & $\begin{array}{l}\text { C14-FA: } 29.2 \% \text { of } \\
\text { DCW }\end{array}$ & & [25] \\
\hline MCFA & po1d pox1-6 $\Delta$ fas1-I1220W & Engineering of native FAS system & $\begin{array}{l}\text { C14-FA: } 2.02 \% \text { of } \\
\text { DCW }\end{array}$ & 11.6 & [55] \\
\hline MCFA & 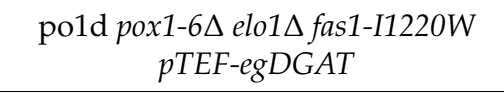 & $\begin{array}{l}\text { Inhibition of native elongation; introduction of } \\
\text { heterologous diacylglycerol acyltransferase }\end{array}$ & C14-FA: $1.25 \mathrm{~g} / \mathrm{L}$ & 45 & {$[56]$} \\
\hline OCFA & $\begin{array}{l}\text { po1d phd1 } 1 \Delta f e 1 \Delta \text { tgl4 } \\
\text { pTEF-DGA2 pTEF-GPD1 }\end{array}$ & $\begin{array}{c}\text { Inhibition of precursor catabolism } \\
\text { (propionyl-CoA); high levels of lipid } \\
\text { accumulation }\end{array}$ & $0.57 \mathrm{~g} / \mathrm{L}$ & 41.9 & [66] \\
\hline OCFA & 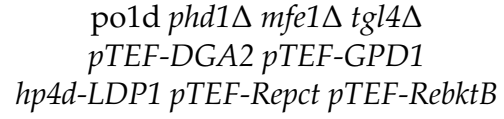 & $\begin{array}{c}\text { Increase in precursor pool size; high levels of } \\
\text { lipid accumulation }{ }^{2}\end{array}$ & $1.87 \mathrm{~g} / \mathrm{L}$ & 62.1 & [67] \\
\hline OCFA & $\begin{array}{c}\text { po1d pox1-6 } \operatorname{tgl} 4 \Delta \text { pTEF-DGA2 } \\
\text { pTEF-GPD1 pTEF-AAT2 } \\
\text { pTEF-THR1 pTEF-THR4 pTEF-ILV1 } \\
\text { pTEF-HOM3 pTEF-HOM2 } \\
\text { pTEF-HOM6 }\end{array}$ & $\begin{array}{l}\text { Overexpression of threonine synthesis pathway; } \\
\text { high levels of lipid accumulation }{ }^{2}\end{array}$ & $0.36 \mathrm{~g} / \mathrm{L}$ & 5.6 & {$[68]$} \\
\hline VLCFA & $\begin{array}{c}\text { po1f pex10A F1::UT-MaELO3 } \\
\text { UT-AtKCS UT-CraKCS UT-EcAldh }\end{array}$ & $\begin{array}{l}\text { Introduction of heterologous } \beta \text {-ketoacyl-CoA } \\
\text { synthases and heterologous elongase; inhibition } \\
\text { of peroxiome biogenesis; increase in precursor } \\
\text { pool size }\end{array}$ & $280 \mathrm{mg} / \mathrm{L}$ & & {$[74]$} \\
\hline VLCFA & po1d fad2 2 pTEF-FAE1 & $\begin{array}{c}\text { Inhibition of } \Delta 12 \text { desaturation; introduction of } \\
\text { heterologous elongase }\end{array}$ & C22:1-FA: $887 \mathrm{mg} / \mathrm{L}$ & 9 & {$[73]$} \\
\hline
\end{tabular}


Table 1. Cont

\begin{tabular}{|c|c|c|c|c|c|}
\hline Product & Strain Genotype & Strategy & Production Details & $\%$ of Total Lipids & Reference \\
\hline CLA & polh $(h p 4 d-o P A I) \times 24$ & $\begin{array}{l}\text { Introduction of heterologous CLA-producing } \\
\text { isomerase with large numbers of gene copies }\end{array}$ & & 5.9 & [79] \\
\hline CLA & $\begin{array}{l}\text { po1h }(\text { hp16d-oPAI }) \times 8 \\
\text { hp4d-MaFAD2 }\end{array}$ & $\begin{array}{l}\text { Introduction of heterologous CLA-producing } \\
\text { isomerase and desaturase }\end{array}$ & $30 \%$ of DCW & 44 & [80] \\
\hline CLA & 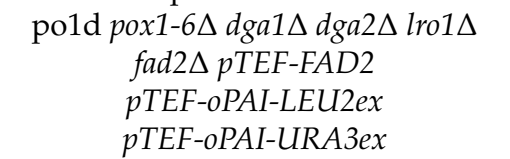 & $\begin{array}{l}\text { Introduction of heterologous CLA-producing } \\
\text { isomerase; overexpression of } F A D 2 \text {; high levels } \\
\text { of lipid accumulation }{ }^{2}\end{array}$ & $302 \mathrm{mg} / \mathrm{L}$ & 6.5 & [81] \\
\hline CLA & $\begin{array}{l}\text { po1h } h p 4 d-P A I \text { hp } 4 d-M A 12 D \\
\text { hp4d-DGA1 }\end{array}$ & $\begin{array}{l}\text { Introduction of heterologous desaturase, } \\
\text { dicylglycerol acyltransferase, and isomerase }\end{array}$ & $132.6 \mathrm{mg} / \mathrm{L}$ & 5.2 & [82] \\
\hline CFA & $\begin{array}{c}\text { po1f pex10 } m f e 1 \Delta \\
\text { UAS1B16-TEF-DGA1 } \\
(U A S 1 B 16-T E F-y c o C F A) \times 2\end{array}$ & $\begin{array}{l}\text { Introduction of heterologous CFA synthase; high } \\
\text { levels of lipid accumulation }{ }^{2}\end{array}$ & C19CP: $3.13 \mathrm{~g} / \mathrm{L}$ & 32.7 & [86] \\
\hline CFA & po1d pox1-6 $\Delta$ tgl4 $\Delta H p 8 d-C F A s$ & $\begin{array}{l}\text { Introduction of heterologous CFA synthase; high } \\
\text { levels of lipid accumulation }{ }^{2}\end{array}$ & $2.3 \mathrm{~g} / \mathrm{L}$ & 45 & [87] \\
\hline CFA & $\begin{array}{l}\text { po1d pox1-6 } \operatorname{tgl} 14 \Delta \text { pTEF-GPD1 } \\
\text { pTEF-DGA2 hp8d-CFA pTEF-LRO1 }\end{array}$ & $\begin{array}{l}\text { Introduction of heterologous CFA synthase; } \\
\text { overexpression of native LRO1; optimization of } \\
\text { carbon source }\end{array}$ & $7.5 \mathrm{~g} / \mathrm{L}$ & 19.6 & [88] \\
\hline RA & 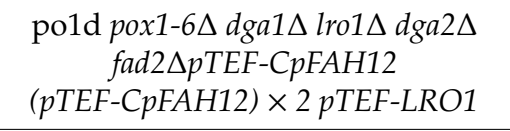 & $\begin{array}{l}\text { Introduction of heterologous fatty acid } \\
\text { hydroxylase; increase in precursor pool size }\end{array}$ & $12 \mathrm{~g} / \mathrm{L}$ & 60 & [98] \\
\hline PUFA & $\begin{array}{c}\text { ATCC } 20362(\triangle 12 D E S) \times 3(\Delta 6 \\
D E S) \times 2(C 18 / 20 E L O) \times 4(\Delta 5 D E S) \\
\times 5(\Delta 17 D E S) \times 3(C 16 / 18 E L O) \times 2\end{array}$ & $\begin{array}{l}\text { Introduction of desaturases and elongases; push } \\
\text { and pull of carbon into the engineered pathway }\end{array}$ & EPA & 40 & [101] \\
\hline PUFA & & $\begin{array}{l}\text { Introduction of desaturases and elongases with } \\
\text { multiple gene copies; inhibition of the } \\
\text { competitive pathway }\end{array}$ & EPA:21.3\% of DCW & 57 & [106] \\
\hline PUFA & Po1h hp4d-Pfa hp4d-PptAf4 & $\begin{array}{l}\text { Introduction of multifunctional polyketide } \\
\text { synthase (PKS)-like PUFA synthases from } \\
\text { Aetherobacter fasciculatus and Minicystis rosea }\end{array}$ & DHA: $350 \mathrm{mg} / \mathrm{L}$ & 16.8 & [107] \\
\hline
\end{tabular}


Table 1. Cont.

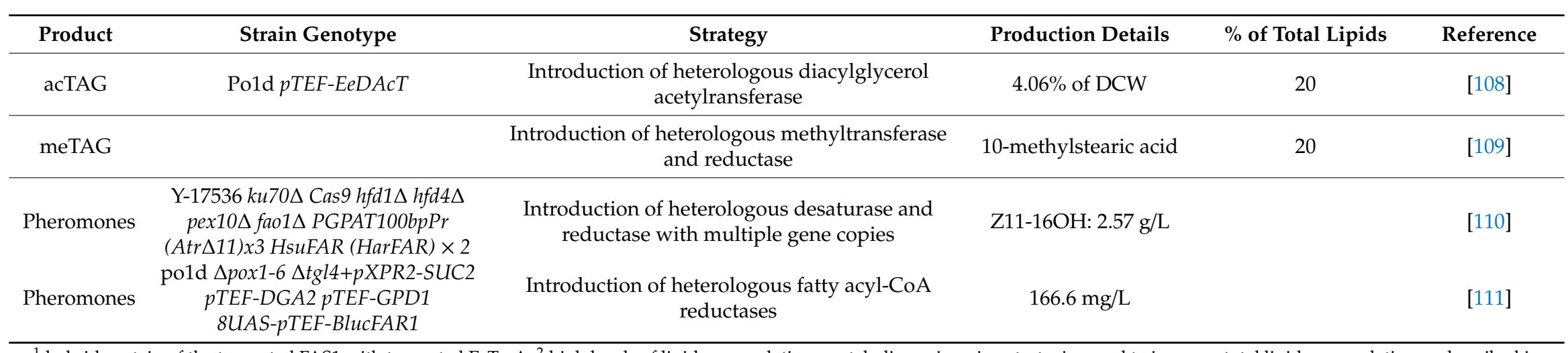

${ }^{1}$ hybrid protein of the truncated FAS1 with truncated EcTesA. ${ }^{2}$ high levels of lipid accumulation: metabolic engineering strategies used to improve total lipid accumulation as described in Section 2.2. The detailed strategies for each strain can be found in Sections 3 and 4 of the text. 
Funding: We would like to acknowledge the Kwanjeong Educational Foundation (KEF) for the PhD scholarship of Young-Kyoung Park. This project received funding from the European Union's Horizon 2020 research and innovation program under grant agreement No 720824 .

Conflicts of Interest: The authors declare no conflict of interest.

\section{Abbreviations}

$\begin{array}{ll}\text { ACPT } & \text { acyl-ACP thioesterase } \\ \text { AcTAGs } & \text { acetylated TAGs } \\ \text { CFA } & \text { cyclopropane fatty acid } \\ \text { CLA } & \text { conjugated linoleic acid } \\ \text { C/N ratio } & \text { carbon-to-nitrogen ratio } \\ \text { DacT } & \text { diacylglycerol acetyltransferase } \\ \text { DAG } & \text { diacylglycerol } \\ \text { DCW } & \text { dry cell weight } \\ \text { DHA } & \text { docosahexaenoic acid } \\ \text { DPA } & \text { docosapentaenoic acid } \\ \text { ECFA } & \text { even-chain fatty acid } \\ \text { EPA } & \text { eicosapentaenoic acid } \\ \text { ER } & \text { endoplasmic reticulum } \\ \text { FA } & \text { fatty acid } \\ \text { FAEE } & \text { fatty acid ethyl ester } \\ \text { FAME } & \text { fatty acid methyl ester } \\ \text { FAS } & \text { fatty acid synthase } \\ \text { FFA } & \text { free fatty acid } \\ \text { KAS } & \text { beta-ketoacyl-ACP synthase } \\ \text { KS } & \text { ketoacyl synthase } \\ \text { LA } & \text { linoleic acid } \\ \text { LB } & \text { lipid body } \\ \text { LCFA } & \text { long-chain fatty acid } \\ \text { LPA } & \text { lysophosphatidic acid } \\ \text { MAG } & \text { monoacylglycerol } \\ \text { MCFA } & \text { medium-chain fatty acid } \\ \text { MFE } & \text { multifunctional enzyme } \\ \text { MPT } & \text { malonyl/palmitoyl transacylase } \\ \text { OCFA } & \text { odd-chain fatty acids } \\ \text { PA } & \text { phosphatidic acid } \\ \text { PCT } & \text { propionyl-CoA transferase } \\ \text { PKT } & \text { polyketide synthase } \\ \text { PPP } & \text { pentose phosphate pathway } \\ \text { PUFA } & \text { polyunsaturated fatty acid } \\ \text { RA } & \text { ricinoleic acid } \\ \text { SCFA } & \text { short-chain fatty acid } \\ \text { TAG } & \text { triacylglycerol } \\ \text { TALEN } & \text { transcription activator-like effector nuclease } \\ \text { VLCFA } & \text { very-long-chain fatty acid } \\ \text { WT } & \text { wild type } \\ & \end{array}$

\section{References}

1. Beopoulos, A.; Nicaud, J.M. Yeast: A new oil producer? OCL-Ol. Corps Gras Lipides 2012, 19, $22-28$. [CrossRef]

2. André, A.; Chatzifragkou, A.; Diamantopoulou, P.; Sarris, D.; Philippoussis, A.; Galiotou-Panayotou, M.; Komaitis, M.; Papanikolaou, S. Biotechnological conversions of bio-dieselderived crude glycerol by strains. Eng. Life Sci. 2009, 9, 468-478. [CrossRef] 
3. Ledesma-Amaro, R.; Nicaud, J.M. Yarrowia lipolytica as a biotechnological chassis to produce usual and unusual fatty acids. Prog. Lipid Res. 2016, 61, 40-50. [CrossRef]

4. Lazar, Z.; Liu, N.; Stephanopoulos, G. Holistic Approaches in Lipid Production by Yarrowia lipolytica. Trends Biotechnol. 2018, 36, 1157-1170. [CrossRef] [PubMed]

5. van de Loo, F.J.; Fox, B.G.; Somerville, C. Unusual fatty acids. In Lipid Metabolism in Plants; Moore, T., Ed.; CRC Press: Boca Raton, FL, USA, 2018; pp. 91-126.

6. Napier, J.A. The Production of Unusual Fatty Acids in Transgenic Plants. Annu. Rev. Plant Biol. 2007, 58, 295-319. [CrossRef]

7. Xie, D.; Jackson, E.N.; Zhu, Q. Sustainable source of omega-3 eicosapentaenoic acid from metabolically engineered Yarrowia lipolytica: From fundamental research to commercial production. Appl. Microbiol. Biotechnol. 2015, 99, 1599-1610. [CrossRef]

8. Aznar-Moreno, J.A.; Durrett, T.P. Simultaneous targeting of multiple gene homeologs to alter seed oil production in Camelina sativa. Plant Cell Physiol. 2017, 58, 1260-1267. [CrossRef]

9. Abdel-Mawgoud, A.M.; Markham, K.A.; Palmer, C.M.; Liu, N.; Stephanopoulos, G.; Alper, H.S. Metabolic engineering in the host Yarrowia lipolytica. Metab. Eng. 2018, 50, 192-208. [CrossRef]

10. Ledesma-Amaro, R.; Lazar, Z.; Rakicka, M.; Guo, Z.; Fouchard, F.; Le Coq, A.M.C.; Nicaud, J.M. Metabolic engineering of Yarrowia lipolytica to produce chemicals and fuels from xylose. Metab. Eng. 2016, 38, 115-124. [CrossRef]

11. Qiao, K.; Wasylenko, T.M.; Zhou, K.; Xu, P.; Stephanopoulos, G. Lipid production in Yarrowia lipolytica is maximized by engineering cytosolic redox metabolism. Nat. Biotechnol. 2017, 35, 173-177. [CrossRef]

12. Friedlander, J.; Tsakraklides, V.; Kamineni, A.; Greenhagen, E.H.; Consiglio, A.L.; MacEwen, K.; Crabtree, D.V.; Afshar, J.; Nugent, R.L.; Hamilton, M.A.; et al. Engineering of a high lipid producing Yarrowia lipolytica strain. Biotechnol. Biofuels 2016, 9, 77. [CrossRef] [PubMed]

13. Larroude, M.; Rossignol, T.; Nicaud, J.M.; Ledesma-Amaro, R. Synthetic biology tools for engineering Yarrowia lipolytica. Biotechnol. Adv. 2018, 36, 2150-2164. [CrossRef] [PubMed]

14. Ganesan, V.; Spagnuolo, M.; Agrawal, A.; Smith, S.; Gao, D.; Blenner, M. Advances and opportunities in gene editing and gene regulation technology for Yarrowia lipolytica. Microb. Cell Fact. 2019, 18, 1-9. [CrossRef] [PubMed]

15. Vorapreeda, T.; Thammarongtham, C.; Cheevadhanarak, S.; Laoteng, K. Alternative routes of acetyl-CoA synthesis identified by comparative genomic analysis: Involvement in the lipid production of oleaginous yeast and fungi. Microbiology 2012, 158, 217-228. [CrossRef] [PubMed]

16. Kamineni, A.; Shaw, J. Engineering triacylglycerol production from sugars in oleaginous yeasts. Curr. Opin. Biotechnol. 2020, 62, 239-247. [CrossRef]

17. Jenni, S.; Leibundgut, M.; Boehringer, D.; Frick, C.; Mikolásek, B.; Ban, N. Structure of fungal fatty acid synthase and implications for iterative substrate shuttling. Science 2007, 316, 254-261. [CrossRef]

18. Lomakin, I.B.; Xiong, Y.; Steitz, T.A. The crystal structure of yeast fatty acid synthase, a cellular machine with eight active sites working together. Cell 2007, 129, 319-332. [CrossRef]

19. Beopoulos, A.; Haddouche, R.; Kabran, P.; Dulermo, T.; Chardot, T.; Nicaud, J.M. Identification and characterization of DGA2, an acyltransferase of the DGAT1 acyl-CoA: Diacylglycerol acyltransferase family in the oleaginous yeast Yarrowia lipolytica. New insights into the storage lipid metabolism of oleaginous yeasts. Appl. Microbiol. Biotechnol. 2012, 93, 1523-1537. [CrossRef]

20. Athenstaedt, K.; Daum, G. Lipid storage: Yeast we can! Eur. J. Lipid Sci. Technol. 2011, 113, $1188-1197$. [CrossRef]

21. Dulermo, T.; Tréton, B.; Beopoulos, A.; Gnankon, A.P.K.; Haddouche, R.; Nicaud, J.M. Characterization of the two intracellular lipases of Yarrowia lipolytica encoded by TGL3 and TGL4 genes: New insights into the role of intracellular lipases and lipid body organisation. Biochim. Biophys. Acta Mol. Cell Biol. Lipids 2013, 1831, 1486-1495. [CrossRef]

22. Dulermo, R.; Gamboa-Meléndez, H.; Dulermo, T.; Thevenieau, F.; Nicaud, J.M. The fatty acid transport protein Fat1p is involved in the export of fatty acids from lipid bodies in Yarrowia lipolytica. FEMS Yeast Res. 2014, 14, 883-896. [CrossRef] [PubMed]

23. Dulermo, R.; Gamboa-Meléndez, H.; Ledesma-Amaro, R.; Thévenieau, F.; Nicaud, J.M. Unraveling fatty acid transport and activation mechanisms in Yarrowia lipolytica. Biochim. Biophys. Acta Mol. Cell Biol. Lipids 2015, 1851, 1202-1217. [CrossRef] [PubMed] 
24. Wang, H.; Le Dall, M.-T.; Waché, Y.; Laroche, C.; Belin, J.M.; Nicaud, J.M. Cloning, sequencing, and characterization of five genes coding for acyl-CoA oxidase isozymes in the yeast Yarrowia lipolytica. Cell Biochem. Biophys. 1999, 31, 165-174. [CrossRef]

25. Xu, P.; Qiao, K.; Ahn, W.S.; Stephanopoulos, G. Engineering Yarrowia lipolytica as a platform for synthesis of drop-in transportation fuels and oleochemicals. Proc. Natl. Acad. Sci. USA 2016, 113, 10848-10853. [CrossRef] [PubMed]

26. Dulermo, T.; Lazar, Z.; Dulermo, R.; Rakicka, M.; Haddouche, R.; Nicaud, J.M. Analysis of ATP-citrate lyase and malic enzyme mutants of Yarrowia lipolytica points out the importance of mannitol metabolism in fatty acid synthesis. Biochim. Biophys. Acta 2015, 1851, 1107-1117. [CrossRef] [PubMed]

27. Tai, M.; Stephanopoulos, G. Engineering the push and pull of lipid biosynthesis in oleaginous yeast Yarrowia lipolytica for biofuel production. Metab. Eng. 2013, 15, 1-9. [CrossRef] [PubMed]

28. Qiao, K.; Imam Abidi, S.H.; Liu, H.; Zhang, H.; Chakraborty, S.; Watson, N.; Kumaran Ajikumar, P.; Stephanopoulos, G. Engineering lipid overproduction in the oleaginous yeast Yarrowia lipolytica. Metab. Eng. 2015, 29, 56-65. [CrossRef] [PubMed]

29. Blazeck, J.; Hill, A.; Liu, L.; Knight, R.; Miller, J.; Pan, A.; Otoupal, P.; Alper, H.S. Harnessing Yarrowia lipolytica lipogenesis to create a platform for lipid and biofuel production. Nat. Commun. 2014, 5, 1-10. [CrossRef] [PubMed]

30. Gajdoš, P.; Ledesma-Amaro, R.; Nicaud, J.M.; Čertík, M.; Rossignol, T. Overexpression of diacylglycerol acyltransferase in Yarrowia lipolytica affects lipid body size, number and distribution. FEMS Yeast Res. 2016, 16, fow062. [CrossRef]

31. Dulermo, T.; Nicaud, J.M. Involvement of the G3P shuttle and B-oxidation pathway in the control of TAG synthesis and lipid accumulation in Yarrowia lipolytica. Metab. Eng. 2011, 13, 482-491. [CrossRef]

32. Beopoulos, A.; Mrozova, Z.; Thevenieau, F.; Le Dall, M.T.; Hapala, I.; Papanikolaou, S.; Chardot, T.; Nicaud, J.M. Control of Lipid Accumulation in the Yeast Yarrowia lipolytica. Appl. Environ. Microbiol. 2008, 74, 7779-7789. [CrossRef] [PubMed]

33. Lazar, Z.; Dulermo, T.; Neuvéglise, C.; Crutz-Le Coq, A.M.; Nicaud, J.M. Hexokinase-A limiting factor in lipid production from fructose in Yarrowia lipolytica. Metab. Eng. 2014, 26, 89-99. [CrossRef] [PubMed]

34. Sagnak, R.; Cochot, S.; Molina-Jouve, C.; Nicaud, J.M.; Guillouet, S.E. Modulation of the Glycerol Phosphate availability led to concomitant reduction in the citric acid excretion and increase in lipid content and yield in Yarrowia lipolytica. J. Biotechnol. 2018, 265, 40-45. [CrossRef] [PubMed]

35. Xue, Z.; Sharpe, P.L.; Hong, S.P.; Yadav, N.S.; Xie, D.; Short, D.R.; Damude, H.G.; Rupert, R.A.; Seip, J.E.; Wang, J. Production of omega-3 eicosapentaenoic acid by metabolic engineering of Yarrowia lipolytica. Nat. Biotechnol. 2013, 31, 734-740. [CrossRef] [PubMed]

36. Dulermo, R.; Dulermo, T.; Gamboa-Meléndez, H.; Thevenieau, F.; Nicaud, J.M. Role of Pex11p in Lipid Homeostasis in Yarrowia lipolytica. Eukaryot. Cell 2015, 14, 511-525. [CrossRef]

37. Liu, L.; Pan, A.; Spofford, C.; Zhou, N.; Alper, H.S. An evolutionary metabolic engineering approach for enhancing lipogenesis in Yarrowia lipolytica. Metab. Eng. 2015, 29, 36-45. [CrossRef] [PubMed]

38. Wynn, J.P.; Hamid, A.A.; Li, Y.; Ratledge, C. Biochemical events leading to the diversion of carbon into storage lipids in the oleaginous fungi Mucor circinelloides and Mortierella alpina. Microbiology 2001, 147, 2857-2864. [CrossRef]

39. Zhang, S.; Ito, M.; Skerker, J.M.; Arkin, A.P.; Rao, C.V. Metabolic engineering of the oleaginous yeast Rhodosporidium toruloides IFO0880 for lipid overproduction during high-density fermentation. Appl. Microbiol. Biotechnol. 2016, 100, 9393-9405. [CrossRef]

40. Zhang, H.; Zhang, L.; Chen, H.; Chen, Y.Q.; Ratledge, C.; Song, Y.; Chen, W. Regulatory properties of malic enzyme in the oleaginous yeast, Yarrowia lipolytica, and its non-involvement in lipid accumulation. Biotechnol. Lett. 2013, 35, 2091-2098. [CrossRef]

41. Wasylenko, T.M.; Ahn, W.S.; Stephanopoulos, G. The oxidative pentose phosphate pathway is the primary source of NADPH for lipid overproduction from glucose in Yarrowia lipolytica. Metab. Eng. 2015, 30, 27-39. [CrossRef]

42. Silverman, A.M.; Qiao, K.; Xu, P.; Stephanopoulos, G. Functional overexpression and characterization of lipogenesis-related genes in the oleaginous yeast Yarrowia lipolytica. Appl. Microbiol. Biotechnol. 2016, 100, 3781-3798. [CrossRef] [PubMed] 
43. Yuzbasheva, E.Y.; Agrimi, G.; Yuzbashev, T.V.; Scarcia, P.; Vinogradova, E.B.; Palmieri, L.; Shutov, A.V.; Kosikhina, I.M.; Palmieri, F.; Sineoky, S.P. The mitochondrial citrate carrier in Yarrowia lipolytica: Its identification, characterization and functional significance for the production of citric acid. Metab. Eng. 2019, 54, 264-274. [CrossRef] [PubMed]

44. Dobrowolski, A.; Mirończuk, A.M. The influence of transketolase on lipid biosynthesis in the yeast Yarrowia lipolytica. Microb. Cell Fact. 2020, 19, 138. [CrossRef] [PubMed]

45. Bhutada, G.; Kavšcek, M.; Ledesma-Amaro, R.; Thomas, S.; Rechberger, G.N.; Nicaud, J.M.; Natter, K. Sugar versus fat: Elimination of glycogen storage improves lipid accumulation in Yarrowia lipolytica. FEMS Yeast Res. 2017, 17. [CrossRef]

46. Biermann, U.; Bornscheuer, U.; Meier, M.A.R.; Metzger, J.O.; Schäfer, H.J. Oils and fats as renewable raw materials in chemistry. Angew. Chemie Int. Ed. 2011, 50, 3854-3871. [CrossRef]

47. Sarria, S.; Kruyer, N.S.; Peralta-Yahya, P. Microbial synthesis of medium-chain chemicals from renewables. Nat. Biotechnol. 2017, 35, 1158-1166. [CrossRef]

48. Lennen, R.M.; Braden, D.J.; West, R.A.; Dumesic, J.A.; Pfleger, B.F. A process for microbial hydrocarbon synthesis: Overproduction of fatty acids in Escherichia coli and catalytic conversion to alkanes. Biotechnol. Bioeng. 2010, 106, 193-202. [CrossRef]

49. Hernández Lozada, N.J.; Lai, R.Y.; Simmons, T.R.; Thomas, K.A.; Chowdhury, R.; Maranas, C.D.; Pfleger, B.F. Highly Active C 8 -Acyl-ACP thioesterase variant isolated by a synthetic selection strategy. ACS Synth. Biol. 2018, 7, 2205-2215. [CrossRef]

50. Jing, F.; Cantu, D.C.; Tvaruzkova, J.; Chipman, J.P.; Nikolau, B.J.; Yandeau-Nelson, M.D.; Reilly, P.J. Phylogenetic and experimental characterization of an acyl-ACP thioesterase family reveals significant diversity in enzymatic specificity and activity. BMC Biochem. 2011, 12, 1-16. [CrossRef]

51. Val, D.; Banu, G.; Seshadri, K.; Lindqvist, Y.; Dehesh, K. Re-engineering ketoacyl synthase specificity. Structure 2000, 8, 565-566. [CrossRef]

52. Gajewski, J.; Pavlovic, R.; Fischer, M.; Boles, E.; Grininger, M. Engineering fungal de novo fatty acid synthesis for short chain fatty acid production. Nat. Commun. 2017, 8. [CrossRef] [PubMed]

53. Zhu, Z.; Hu, Y.; Teixeira, P.G.; Pereira, R.; Chen, Y.; Siewers, V.; Nielsen, J. Multidimensional engineering of Saccharomyces cerevisiae for efficient synthesis of medium-chain fatty acids. Nat. Catal. 2020, 3, 64-74. [CrossRef]

54. Rutter, C.D.; Zhang, S.; Rao, C.V. Engineering Yarrowia lipolytica for production of medium-chain fatty acids. Appl. Microbiol. Biotechnol. 2015, 99, 7359-7368. [CrossRef] [PubMed]

55. Rigouin, C.; Gueroult, M.; Croux, C.; Dubois, G.; Borsenberger, V.; Barbe, S.; Marty, A.; Daboussi, F.; André, I.; Bordes, F. Production of medium chain fatty acids by Yarrowia lipolytica: Combining molecular design and TALEN to engineer the fatty acid synthase. ACS Synth. Biol. 2017, 6, 1870-1879. [CrossRef] [PubMed]

56. Rigouin, C.; Croux, C.; Borsenberger, V.; Ben Khaled, M.; Chardot, T.; Marty, A.; Bordes, F. Increasing medium chain fatty acids production in Yarrowia lipolytica by metabolic engineering. Microb. Cell Fact. 2018, 17, 142. [CrossRef] [PubMed]

57. Degwert, J. Use of cis-9-heptadecenoic Acid for Treating Psoriasis and Allergies. U.S. Patent 5708028A, 1994. [CrossRef]

58. Avis, T.J. Synthesis and biological characterization of (Z)-9-heptadecenoic and (Z)-6-methyl-9-heptadecenoic acids: Fatty acids with antibiotic activity produced by Pseudozyma flocculosa. J. Chem. Ecol. 2000, 26, 987-1000. [CrossRef]

59. Clausen, C.A.; Coleman, R.D.; Yang, V.W. Fatty acid-based formulations for wood protection against mold and sapstain. For. Prod. J. 2010, 60, 301-304. [CrossRef]

60. Köckritz, A.; Blumenstein, M.; Martin, A. Catalytic cleavage of methyl oleate or oleic acid. Eur. J. Lipid Sci. Technol. 2010, 112, 58-63. [CrossRef]

61. Fitton, A.; Goa, K.L. Azelaic Acid: A Review of its pharmacological properties and therapeutic efficacy in acne and hyperpigmentary skin disorders. Drugs 1991, 41, 780-798. [CrossRef]

62. Ingram, L.O.; Chevalier, L.S.; Gabbay, E.J. Priopionate-induced synthesis of odd-chain-length fatty acids by Escherichia coli. J. Bacteriol. 1977, 131, 1023-1025. [CrossRef]

63. Wu, H.; San, K.Y. Efficient odd straight medium chain free fatty acid production by metabolically engineered Escherichia coli. Biotechnol. Bioeng. 2014, 111, 2209-2219. [CrossRef] [PubMed] 
64. Fontanille, P.; Kumar, V.; Christophe, G.; Nouaille, R.; Larroche, C. Bioconversion of volatile fatty acids into lipids by the oleaginous yeast Yarrowia lipolytica. Bioresour. Technol. 2012, 114, 443-449. [CrossRef] [PubMed]

65. Kolouchová, I.; Schreiberová, O.; Sigler, K.; Masák, J.; Řezanka, T. Biotransformation of volatile fatty acids by oleaginous and non-oleaginous yeast species. FEMS Yeast Res. 2015, 15, 1-8. [CrossRef] [PubMed]

66. Park, Y.K.; Dulermo, T.; Ledesma-Amaro, R.; Nicaud, J.M. Optimization of odd chain fatty acid production by Yarrowia lipolytica. Biotechnol. Biofuels 2018, 11, 1-12. [CrossRef] [PubMed]

67. Park, Y.K.; Bordes, F.; Letisse, F.; Nicaud, J.M. Engineering precursor pools for increasing production of odd-chain fatty acids in Yarrowia lipolytica. bioRxiv 2020. [CrossRef]

68. Park, Y.K.; Ledesma-Amaro, R.; Nicaud, J.M. De novo biosynthesis of odd-chain fatty acids in Yarrowia lipolytica enabled by modular pathway engineering. Front. Bioeng. Biotechnol. 2020, 7. [CrossRef] [PubMed]

69. Wisniak, J. Potential uses of jojoba oil and meal-A review. Ind. Crops Prod. 1994, 3, 43-68. [CrossRef]

70. Jannin, V.; Cuppok, Y. Hot-melt coating with lipid excipients. Int. J. Pharm. 2013, 457, 480-487. [CrossRef]

71. Wenning, L.; Yu, T.; David, F.; Nielsen, J.; Siewers, V. Establishing very long-chain fatty alcohol and wax ester biosynthesis in Saccharomyces cerevisiae. Biotechnol. Bioeng. 2017, 114, 1025-1035. [CrossRef]

72. Yu, T.; Zhou, Y.J.; Wenning, L.; Liu, Q.; Krivoruchko, A.; Siewers, V.; Nielsen, J.; David, F. Metabolic engineering of Saccharomyces cerevisiae for production of very long chain fatty acid-derived chemicals. Nat. Commun. 2017, 8, 1-10. [CrossRef]

73. Gajdoš, P.; Hambalko, J.; Slaný, O.; Čertík, M. Conversion of waste materials into very long chain fatty acids by the recombinant yeast Yarrowia lipolytica. FEMS Microbiol. Lett. 2019, 367, 1-8. [CrossRef] [PubMed]

74. Gao, Q.; Yang, J.L.; Zhao, X.R.; Liu, S.C.; Liu, Z.J.; Wei, L.J.; Hua, Q. Yarrowia lipolytica as a metabolic engineering platform for the production of very-long-chain wax esters. J. Agric. Food Chem. 2020, 68, 10730-10740. [CrossRef] [PubMed]

75. Crumb, D.; Vattem, D. Conjugated linoleic acid (CLA)-An overview. Int. J. Appl. Res. Nat. Prod. 2011, 4, $12-15$.

76. Kishino, S.; Ogawa, J.; Omura, Y.; Matsumura, K.; Shimizu, S. Conjugated linoleic acid production from linoleic acid by lactic acid bacteria. J. Am. Oil Chem. Soc. 2002, 79, 159-163. [CrossRef]

77. Ando, A.; Ogawa, J.; Kishino, S.; Shimizu, S. Conjugated linoleic acid production from castor oil by Lactobacillus plantarum JCM 1551. Enzyme Microb. Technol. 2004, 35, 40-45. [CrossRef]

78. Hornung, E.; Krueger, C.; Pernstich, C.; Gipmans, M.; Porzel, A.; Feussner, I. Production of (10E,12Z)-conjugated linoleic acid in yeast and tobacco seeds. Biochim. Biophys. Acta Mol. Cell Biol. Lipids 2005, 1738, 105-114. [CrossRef]

79. Zhang, B.; Rong, C.; Chen, H.; Song, Y.; Zhang, H.; Chen, W. De novo synthesis of trans-10, cis-12 conjugated linoleic acid in oleaginous yeast Yarrowia lipolytica. Microb. Cell Fact. 2012, 11, 51. [CrossRef]

80. Zhang, B.; Chen, H.; Li, M.; Gu, Z.; Song, Y.; Ratledge, C.; Chen, Y.Q.; Zhang, H.; Chen, W. Genetic engineering of Yarrowia lipolytica for enhanced production of trans-10, cis-12 conjugated linoleic acid. Microb. Cell Fact. 2013, 12, 70. [CrossRef]

81. Imatoukene, N.; Verbeke, J.; Beopoulos, A.; Idrissi Taghki, A.; Thomasset, B.; Sarde, C.O.; Nonus, M.; Nicaud, J.M. A metabolic engineering strategy for producing conjugated linoleic acids using the oleaginous yeast Yarrowia lipolytica. Appl. Microbiol. Biotechnol. 2017, 101, 4605-4616. [CrossRef]

82. Wang, X.; Xia, Q.; Wang, F.; Zhang, Y.; Li, X. Modulating heterologous pathways and optimizing culture conditions for biosynthesis of trans-10, cis-12 conjugated linoleic acid in Yarrowia lipolytica. Molecules 2019, 24, 1753. [CrossRef]

83. Svensson, L.; Hansson, U.; Gronowitz, S.; Klingstedt, T. The relationship between the structure of monoalkyl branched saturated triacylglycerols and some physical properties. Lipids 1997, 32, 661-666. [CrossRef] [PubMed]

84. Cronan, J.E.; Reed, R.; Taylor, F.R.; Jackson, M.B. Properties and biosynthesis of cyclopropane fatty acids in Escherichia coli. J. Bacteriol. 1979, 138, 118-121. [CrossRef] [PubMed]

85. Schmid, K.M. Cyclopropane Fatty Acid Expression in Plants. U.S. Patent 5936139A, 1999.

86. Markham, K.A.; Alper, H.S. Engineering Yarrowia lipolytica for the production of cyclopropanated fatty acids. J. Ind. Microbiol. Biotechnol. 2018, 45, 881-888. [CrossRef] [PubMed]

87. Czerwiec, Q.; Idrissitaghki, A.; Imatoukene, N.; Nonus, M.; Thomasset, B.; Nicaud, J.M.; Rossignol, T. Optimization of cyclopropane fatty acids production in Yarrowia lipolytica. Yeast 2019, 36, 143-151. [CrossRef] [PubMed] 
88. Imatoukene, N.; Back, A.; Nonus, M.; Thomasset, B.; Rossignol, T.; Nicaud, J.M. Fermentation process for producing CFAs using Yarrowia lipolytica. J. Ind. Microbiol. Biotechnol. 2020, 47, 403-412. [CrossRef]

89. Mutlu, H.; Meier, M.A.R. Castor oil as a renewable resource for the chemical industry. Eur. J. Lipid Sci. Technol. 2010, 112, 10-30. [CrossRef]

90. Da Silva, N.L.; Maciel, M.R.W.; Batistella, C.B.; Filho, R.M. Optimization of biodiesel production from castor oil. J. Environ. Chem. Eng. 2018, 6, 2684-2695. [CrossRef]

91. Ogunniyi, D.S. Castor oil: A vital industrial raw material. Bioresour. Technol. 2006, 97, 1086-1091. [CrossRef]

92. Broun, P.; Somerville, C. Accumulation of ricinoleic, lesquerolic, and densipolic acids in seeds of transgenic Arabidopsis plants that express a fatty acyl hydroxylase cDNA from castor bean. Plant Physiol. 1997, 113, 933-942. [CrossRef]

93. Lu, C.; Fulda, M.; Wallis, J.G.; Browse, J. A high-throughput screen for genes from castor that boost hydroxy fatty acid accumulation in seed oils of transgenic Arabidopsis. Plant J. 2006, 45, 847-856. [CrossRef]

94. Burgal, J.; Shockey, J.; Lu, C.; Dyer, J.; Larson, T.; Graham, I.; Browse, J. Metabolic engineering of hydroxy fatty acid production in plants: RcDGAT2 drives dramatic increases in ricinoleate levels in seed oil. Plant Biotechnol. J. 2008, 6, 819-831. [CrossRef] [PubMed]

95. Holic, R.; Yazawa, H.; Kumagai, H.; Uemura, H. Engineered high content of ricinoleic acid in fission yeast Schizosaccharomyces pombe. Appl. Microbiol. Biotechnol. 2012, 95, 179-187. [CrossRef]

96. Yazawa, H.; Ogiso, M.; Kumagai, H.; Uemura, H. Suppression of ricinoleic acid toxicity by ptl2 overexpression in fission yeast Schizosaccharomyces pombe. Appl. Microbiol. Biotechnol. 2014, 98, 9325-9337. [CrossRef] [PubMed]

97. Meesapyodsuk, D.; Chen, Y.; Ng, S.H.; Chen, J.; Qiu, X. Metabolic engineering of Pichia pastoris to produce ricinoleic acid, a hydroxy fatty acid of industrial importance. J. Lipid Res. 2015, 56, 2102-2109. [CrossRef] [PubMed]

98. Beopoulos, A.; Verbeke, J.; Bordes, F.; Guicherd, M.; Bressy, M.; Marty, A.; Nicaud, J.M. Metabolic engineering for ricinoleic acid production in the oleaginous yeast Yarrowia lipolytica. Appl. Microbiol. Biotechnol. 2014, 98, 251-262. [CrossRef] [PubMed]

99. Robin, J.; Gueroult, M.; Cheikhrouhou, R.; Guichard, M.; Borsenberger, V.; Marty, A.; Bordes, F. Identification of a crucial amino acid implicated in the hydroxylation/desaturation ratio of CpFAH12 bifunctional hydroxylase. Biotechnol. Bioeng. 2019, 116, 2451-2462. [CrossRef]

100. Guo, Z.P.; Robin, J.; Duquesne, S.; O’Donohue, M.J.; Marty, A.; Bordes, F. Developing cellulolytic Yarrowia lipolytica as a platform for the production of valuable products in consolidated bioprocessing of cellulose. Biotechnol. Biofuels 2018, 11, 141. [CrossRef]

101. Zhu, Q.; Xue, Z.; Yadav, N.; Damude, H.; Pollak, D.W.; Rupert, R.; Seip, J.; Hollerbach, D.; Macool, D.; Zhang, H. Metabolic Engineering of an Oleaginous Yeast for the Production of Omega-3 Fatty Acids, 2nd ed.; Academic Press and AOCS Press: Urbana, IL, USA, 2010; pp. 51-73. [CrossRef]

102. Domingo, J.L. Omega-3 fatty acids and the benefits of fish consumption: Is all that glitters gold? Environ. Int. 2007, 33, 993-998. [CrossRef]

103. Martins, D.A.; Custódio, L.; Barreira, L.; Pereira, H.; Ben-Hamadou, R.; Varela, J.; Abu-Salah, K.M. Alternative sources of n-3 long-chain polyunsaturated fatty acids in marine microalgae. Mar. Drugs 2013, 11, 2259-2281. [CrossRef]

104. Maccol, D.J.; Xue, Z.; Zhu, Q.Q. Mortierella Alpina C16/18 Fatty Acid Elongase. U.S. Patent 7470532B2, 2008.

105. Narendra, S.; Yadav, Q.Q.; Zhu, H.Z. $\Delta 12$ Desaturases Suitable for Altering Levels of Polyunsaturated Fatty Acids in Oleaginous Yeast. U.S. Patent 7504259B, 2009.

106. Hong, S.P.; Sharpe, P.L.; Xue, Z.; Yadav, N.S. Improved Optimized Strains of Yarrowia lipolytica for High Eicosapentaenoic Acid Production. U.S. Patent 7645604, 2010.

107. Gemperlein, K.; Dietrich, D.; Kohlstedt, M.; Zipf, G.; Bernauer, H.S.; Wittmann, C.; Wenzel, S.C.; Müller, R. Polyunsaturated fatty acid production by Yarrowia lipolytica employing designed myxobacterial PUFA synthases. Nat. Commun. 2019, 10,1-12. [CrossRef]

108. Gajdoš, P.; Hambalko, J.; Nicaud, J.M.; Čertík, M. Overexpression of diacylglycerol acetyltransferase from Euonymus europaeus in Yarrowia lipolytica leads to the production of single-cell oil enriched with 3-acetyl-1,2-diacylglycerols. Yeast 2020, 37, 141-147. [CrossRef] [PubMed]

109. Shaw, A.J.; Blitzblau, H.; Crabtree, D.V. Heterologous Production of 10-methylstearic Acid. U.S. Patent 20200123579A1, 2020. 
110. Holkenbrink, C.; Ding, B.J.; Wang, H.L.; Dam, M.I.; Petkevicius, K.; Kildegaard, K.R.; Wenning, L.; Sinkwitz, C.; Lorántfy, B.; Koutsoumpeli, E. Production of moth sex pheromones for pest control by yeast fermentation. Metab. Eng. 2020, 62, 312-321. [CrossRef] [PubMed]

111. Hambalko, J.; Gajdoš, P.; Nicaud, J.M.; Ledesma-Amaro, R.; Tupec, M.; Pichová, I.; Čertík, M. Expression of bumble bee reductases BlucFAR1 and BlapFAR4 in Yarrowia lipolytica. Front. Bioeng. Biotechnol. under revision.

Publisher's Note: MDPI stays neutral with regard to jurisdictional claims in published maps and institutional affiliations.

(C) 2020 by the authors. Licensee MDPI, Basel, Switzerland. This article is an open access article distributed under the terms and conditions of the Creative Commons Attribution (CC BY) license (http://creativecommons.org/licenses/by/4.0/). 